\title{
Multi-glycoside of Tripterygium wilfordii Hook. f. ameliorates imiquimod-induced skin lesions through a STAT3-dependent mechanism involving the inhibition of Th17-mediated inflammatory responses
}

\author{
JINGXIA ZHAO ${ }^{1,2}$, TINGTING DI ${ }^{1}$, YAN WANG $^{1}$, XIN LIU $^{1}$, \\ DAIYING LIANG ${ }^{1}$, GUANGZHONG ZHANG ${ }^{2}$ and PING LI ${ }^{1,2}$

\begin{abstract}
${ }^{1}$ Department of Pathophysiology, Beijing Key Laboratory of Clinic and Basic Research
with Traditional Chinese Medicine on Psoriasis, Beijing Institute of Traditional Chinese Medicine, Beijing 100010;

${ }^{2}$ Beijing Hospital of Traditional Chinese Medicine, Affiliated with Capital Medical University, Beijing 100010, P.R. China
\end{abstract}

Received May 22, 2015; Accepted June 7, 2016

DOI: $10.3892 /$ ijmm.2016.2670

\begin{abstract}
Multi-glycoside of Tripterygium wilfordii Hook. f. (GTW) possesses anti-inflammatory and immunosuppressive properties, and has been used as a traditional treatment for psoriasis for many years, although the underlying immunological mechanisms remain poorly understood. The T helper (Th)17 cell response is considered to play a major role in the pathogenesis of psoriasis. Th17 cells are implicated in the mechanism of pathogenesis of imiquimod (IMQ)-induced skin inflammation. Using a mouse model, we demonstrated that GTW protected mice from developing psoriasis-like lesions induced by topical IMQ administration. This protection was associated with significantly decreased mRNA levels of Th17 cytokines such as interleukin (IL)-17A, IL-17F and IL-22 in mouse skin samples as well as fewer IL-17-secreting splenic $\mathrm{CD}^{+}$lymphocytes in IMQ-exposed mice. There were no significant effects on the proportion of $\mathrm{CD}^{+}{ }^{+}$interferon (IFN) $\gamma^{+} \mathrm{T}$ cells, CD4 $4^{+} \mathrm{IL}-4^{+}$ $\mathrm{T}$ cells and $\mathrm{CD} 4^{+} \mathrm{CD} 25^{+} \mathrm{Foxp} 3^{+}$Treg cells in the spleen cells. Taken together with the unchanged mRNA levels of Th1 cytokine IFN- $\gamma$, Th2 cytokine IL-4 and Treg cytokine IL-10 in IMQ-exposed mouse skin following GTW administration, our findings suggest that the immunosuppressive effect of GTW in psoriasis is exerted mainly on Th17 cells, rather than on Th1, Th2 or Treg cells. Furthermore, we showed that GTW suppressed Th17 function through the inhibition of STAT3 phosphorylation. These results have the potential to pave the way for the use of GTW as an agent for the treatment of psoriasis.
\end{abstract}

Correspondence to: Dr Ping Li, Department of Pathophysiology, Beijing Key Laboratory of Clinic and Basic Research with Traditional Chinese Medicine on Psoriasis, Beijing Institute of Traditional Chinese Medicine, 23 Meishuguan Back Street, Dongcheng, Beijing 100010, P.R. China

E-mail: liping411@163.com

Key words: multi-glycoside of Tripterygium wilfordii Hook. f., psoriasis, T helper 17 cells, inflammation, STAT3, imiquimod

\section{Introduction}

Psoriasis is a common skin disorder that affects $2 \%$ of the worldwide population (1). Typical lesions are sharply demarcated, thick, erythematous, scaly plaques. Histologically, it is characterized by epidermal acanthosis, papillomatosis and parakeratosis, infiltrating leukocytes and neutrophils in the epidermis and dermis, as well as neoangiogenesis (2).

Psoriasis is recognized as an organ-specific autoimmune disease that is triggered by an activated cellular immune system $(3,4)$. Although psoriasis has traditionally been classified as a Thelper (Th)1-mediated disease due to the abundance of interferon (IFN)- $\gamma$-producing Th1-polarized T cells within psoriatic skin (5), several studies have highlighted the significance of Th17 cells. Th17 cells are a newly identified population of interleukin (IL)-17-producing Th cells shown to be involved in the pathogenesis of psoriasis and other autoimmune inflammatory disorders (6-8). The development and maintenance of Th17 cells is driven by IL-23, a key cytokine which initiates the development of autoimmunity $(9,10)$. IL-23, secreted by skin dendritic cells (DCs), induces Th17 cell production of proinflammatory cytokines, such as IL-17A, IL-17F, tumor necrosis factor- $\alpha($ TNF- $\alpha)$ and IL-22. The cytokine components of the Th17 cells play vital roles in human psoriasis (11). These mediators act on keratinocytes leading to their activation and hyperproliferation. In the cross-talk between keratinocytes and Th17 cells, activated keratinocytes produce key proinflammatory cytokines, chemokines and antimicrobial peptides, which recruit and activate immune cells in the inflamed skin $(12,13)$. These events result in amplification of the immune response leading to the clinical features of the disease.

Tripterygium wilfordii Hook. $\mathrm{f}$. is a traditional medicinal herb which has been used for several centuries in China. One component found in extracts of this plant is a stable glycoside, known as multi-glycoside of $T$. wilfordii Hook. f. (GTW). It is comprised of trace diterpenes, a small quantity of alkaloids and some pentacyclic triterpenes. It is generally considered that the most toxic components of T. wilfordii Hook.f. are 
diterpenoids followed by alkaloids, and GTW is the least toxic compound (14). GTW has been shown to exert anti-inflammatory and immunosuppressive effects and has been used for the clinical treatment of psoriasis for many years (15). However, the precise immunological mechanisms underlying the therapeutic effects of GTW on psoriasis remain poorly understood.

Recently, the topical administration of imiquimod (IMQ) to mice, a ligand for Toll-like receptor (TLR)7 and TLR8, was shown to induce psoriasis-like skin inflammation, including characteristics such as acanthosis, parakeratosis and inflammatory cell infiltration (16). In the present study, we examined the effects of GTW on psoriasis-like lesions induced by topical IMQ administration in a mouse model, as well as the underlying mechanisms. Our results provide evidence that GTW protected the mice against IMQ-induced psoriasis-like inflammation through a mechanism involving the inhibition of STAT3 phosphorylation in Th17-mediated inflammatory responses.

\section{Materials and methods}

Mice and treatments. Fifty mice (BALB/c, aged 8 weeks) were purchased from the Experimental Animal Center of the Chinese Academy of Medical Sciences (Beijing, China), the dorsal area was shaved and the mice were randomly divided into the following five groups (10 mice/group): i) the normal control group (normal) which received applications of appropriate Vaseline spread on the exposed back regularly each day and intragastric administration of saline $(0.4 \mathrm{ml} /$ day $)$ for 8 continuous days; ii) the model group which received regular applications of $42 \mathrm{mg}$ of 5\% IMQ cream on the exposed back each day and intragastric administration of saline $(0.4 \mathrm{ml} /$ day) for 8 continuous days; and iii-v) the treatment groups which received low-, medium- and high-doses of GTW (10, 20 and $40 \mathrm{mg} / \mathrm{kg}$, respectively) by intragastric administration of GWT solution ( $0.4 \mathrm{ml} /$ day) and regular applications of $42 \mathrm{mg}$ of 5\% IMQ cream on the exposed back each day and intragastric administration of GWT solution $(0.4 \mathrm{ml} /$ day $)$ for 8 continuous days. The GTW used in this study was provided by DND Pharmaceutical Co., Ltd. (Zhejiang, China). It was solubilized in sterile distilled water and administered to the GTW group intragastrically via gavage $(10,20$ and $40 \mathrm{mg} / \mathrm{kg})$ once per day in parallel with the IMQ administration from day 1 to 8 . All mice were kept under pathogen-free conditions and provided with food and water ad libitum. Six mice in each group at day 4 or 8 were sacrificed. The mice were sacrificed by cervical dislocation and the spleens were removed and weighed. All animal experiments were performed in accordance with the National Institutes of Health Guidelines on Laboratory Research and approved by the Animal Ethics Committee of Capital Medical University (Beijing, China).

Severity scoring of skin inflammation. To score the severity of the inflammation induced in the skin, an objective scoring system was developed based on the clinical Psoriasis Area and Severity Index (PASI). However, the scoring system for the mouse model did not take into account the affected skin area in the overall score. Erythema, scaling, and thickening were scored independently on a scale from 0 to 4 : 0 , none; 1 , slight; 2 , moderate; 3 , marked; 4 , very marked. The cumulative score (erythema plus scaling plus thickening) served as a measure of the severity of inflammation (scale 0-12). For score evaluation, 6 mice were taken from each group per day.

Skin histology and immunohistochemical (IHC) staining. Tissue samples were taken from 6 mice in each group on days 4 or 8 in accordance with the following procedure: i) skin tissue samples were incised from the corresponding lesions using a nine-grid method; part of the tissue sample was embedded in optimal cutting temperature (OCT) compound for the preparation of frozen sections; ii) part of the tissue sample was stored in liquid nitrogen for mRNA and protein detection; iii) the remaining part of the tissue sample was fixed in formalin for the preparation of paraffin sections.

IMQ-exposed, psoriasis-like inflammatory skin was paraffin-embedded, sectioned and stained with hematoxylin and eosin (H\&E) and the epidermal thickness was determined using Image Pro Plus 6.0 software under a microscope (BX51; Olympus, Tokyo, Japan) in a blinded manner.

For IHC staining, the paraffin sections were deparaffinized and hydrated by washing the sections in xylene for $20 \mathrm{~min}$, followed by a graded series of alcohol at concentrations from 70 to $100 \%$. To unmask antigens, the sections were incubated in $10 \mathrm{mM}$ citric acid $(\mathrm{pH} 6.0)$ at $95^{\circ} \mathrm{C}$ for $20 \mathrm{~min}$. Endogenous peroxidase activity was quenched by treating the sections with $3 \%$ hydrogen peroxide for $10 \mathrm{~min}$ at room temperature. The sections were then incubated with primary antibodies including anti-CD3 (Cat. no. ab16669) and anti-proliferating cell nuclear antigen (PCNA; Cat. no. ab29) (both from Abcam, Cambridge, UK); as well as anti-F4/80 (Cat. no. 123106; BioLegend, Inc., San Diego, CA, USA) overnight at $4^{\circ} \mathrm{C}$ in buffer. This was followed by incubation with biotin-linked secondary antibody (Abcam) for $30 \mathrm{~min}$. Finally, 3,3'-diaminobenzidine (DAB) or NovaRED substrate (Vector Laboratories, Inc., Burlingame,CA, USA) was used for chromogenic detection. The cryosections were fixed, blocked and then stained with rat-anti-mouse Gr-1 (Cat. no. 550291; BD Pharmingen, San Jose, CA, USA) followed by secondary antibody (Vectastain Elite ABC kit; Vector Laboratories, Inc.). The slides were developed with NovaRED substrate solution (Vector Laboratories, Inc.). Additional slides were stained with FITC-conjugated anti-mouse $\gamma \delta$ TCR (Cat. no. 118105, BioLegend, Inc.) or involucrin antibody (Cat. no. ab28057; Abcam) and DAPI to visualize the nuclei. All the stained sections were counterstained with hematoxylin (BASO Diagnostics Inc., Zhuhai, China). The sections from at least six mice/group were stained, and the images were captured at $\mathrm{x} 200$ or $\mathrm{x} 400$ magnification using a microscope (BX51; Olympus) with a digital charge-coupled device (CCD) camera (DP72; Olympus).

Flow cytometric analysis. Spleen samples from each group were minced through a $70 \mu \mathrm{m}$ mesh to obtain single cell suspensions. For flow cytometric analysis, $1 \times 10^{6}$ cells were fixed and permeabilized with Cytofix/Cytoperm (BD Pharmingen) stained with fluorescein isothiocyanate (FITC)-conjugated mouse monoclonal anti-CD4 and allophycocyanin (APC)conjugated anti-CD25, and phycoerythrin (PE)-conjugated mouse anti-Foxp3 (all from eBioscience, San Diego, CA, USA). For the detection of intracellular cytokines, $1 \times 10^{6}$ spleen cells were stimulated with phorbol myristate acetate (PMA) in $10 \mathrm{ng} /$ $\mathrm{ml}$ phosphate-buffered saline (PBS) and ionomycin $1 \mu \mathrm{g} / \mathrm{ml}$ in 
Table I. Primers used for RT-qPCR.

Primer sequences

\begin{tabular}{ll}
\hline IL-23 & F: 5'-GACTCAGCCAACTCCTCCAGCCAG-3' \\
& R: 5'-TTGGCACTAAGGGCTCAGTCAGA-3' \\
IL-17A & F: 5'-CAGACTACCTCAACCGTTCCA-3' \\
& R: 5'-ACAATCGAGGCCACGCAGGTGCAGC-3' \\
IL-17F & F: 5'-TGCTACTGTTGATGTTGGGAC-3' \\
& R: 5'-AATGCCCTGGTTTTGGTTGAA-3' \\
IL-22 & F: 5'-CGTCAACCGCACCTTTAT-3' \\
& R: 5'-AGGGCTGGAACCTGTCTG-3' \\
TNF- $\alpha$ & F: 5'-GAGAAGTTCCCAAATGGC-3' \\
& R: 5'-ACTTGGTGGTTTGCTACG-3' \\
ROR $\gamma \mathrm{t}$ & F: 5'-AGTATGTGGTGGAGTTTGC-3' \\
& R: 5'-TAGGACGACTTCCATTGCT-3' \\
IFN- $\gamma$ & F: 5'-TAACTCAAGTGGCATAGATGTGGAAG-3' \\
& R: 5'-GACGCTTATGTTGTTGCTGATGG-3' \\
IL-10 & F: 5'-CTGGACAACATACTGCTAACCGACTC-3' \\
& R: 5'-AACTGGATCATTTCCGATAAGGC-3' \\
K14 & F: 5'-ACGCCCACCTTTCATCTTCCCAAT-3' \\
& R: 5'-ATCTGGCGGTTGGTGGAGGTCA-3' \\
Foxp3 & F: 5'-CCCATCCCCAGGAGTCTTG-3' \\
& R: 5'-ACCATGACTAGGGGCACTGTA-3' \\
& F: 5'-TCGTCTGTAGGGCTTCCAAGGTGCT-3' \\
& R: 5'-GTGGACTTGGACTCATTCATGGTGC-3' \\
& R: 5'-GGCATAGAGGTCTTTACGG-3' \\
&
\end{tabular}

F, forward; R, reverse; IL, interleukin; TNF- $\alpha$, tumor necrosis factor- $\alpha$; IFN- $\gamma$, interferon- $\gamma$; K14, keratin 14; retinoic acid-related orphan receptor $\gamma \mathrm{t}, \mathrm{ROR} \gamma \mathrm{t}$.

PBS (Sigma, St. Louis, CA, USA) in the presence of GolgiStop (eBioscience) for $5 \mathrm{~h}$. The cells were harvested and stained with FITC-conjugated anti-CD4 (eBioscience), followed by intracellular staining using mouse monoclonal antibodies: PE-conjugated anti-IL-17A, APC-conjugated anti-IFN- $\gamma$, and APC-conjugated anti-IL-4 (all from BD Pharmingen) after fixation and permeabilization with Cytofix/Cytoperm (BD Pharmingen). Inguinal lymph nodes were separated and ground by the $50 \mu \mathrm{m}$ nylon membrane using sterile technique. The cells were stained with APC-conjugated anti-CD3 (eBioscience) and PE-conjugated anti- $\gamma \delta$ TCR (BD Pharmingen). The samples were analyzed on a flow cytometer (FACSCanto) using CellQuest software (both from BD Biosciences, Franklin Lakes, NJ, USA). The expression levels of intracellular IL-17, IFN- $\gamma$, IL-4 and Foxp3 were analyzed.

Isolation of naive $C D 4^{+} T$ cells and in vitro induction and culture of Th17 cells. The $\mathrm{CD} 4{ }^{+} \mathrm{CD} 62 \mathrm{~L}^{+} \mathrm{T}$ cell Iso kit II (Miltenyi Biotec, Bergisch Gladbach, Germany) was adopted for the direct sorting of the naive $\mathrm{CD} 4^{+} \mathrm{T}$ cells. A single-cell suspension was prepared by the mild grinding of the spleen samples and the $\mathrm{CD} 4{ }^{+} \mathrm{CD} 62 \mathrm{~L}^{+} \mathrm{T}$ cells were isolated according to the manufacturer's instructions.

The $\mathrm{CD} 4{ }^{+} \mathrm{CD} 62 \mathrm{~L}^{+} \mathrm{T}$ cells were seeded in 12-well plates $\left(2 \times 10^{6} /\right.$ well $)$ or 96 -well plates $\left(5 \times 10^{4} /\right.$ well) which were coated with anti-CD3 $(5 \mu \mathrm{g} / \mathrm{ml})$ and anti-CD28 $(2 \mu \mathrm{g} / \mathrm{ml})$ and well mixed and cultured with complete RPMI-1640 medium containing transforming growth factor (TGF)- $\beta 1$ ( $5 \mathrm{ng} / \mathrm{ml})$, IL-6 (20 ng/ $\mathrm{ml})$, IL-1 $\beta(10 \mathrm{ng} / \mathrm{ml})$, anti-IL-2 $(10 \mu \mathrm{g} / \mathrm{ml})$, anti-IL-4 $(10 \mu \mathrm{g} / \mathrm{ml})$, anti-IFN- $\gamma(10 \mu \mathrm{g} / \mathrm{ml})$, IL-23 $(15 \mathrm{ng} / \mathrm{ml})$ and $10 \%$ fetal bovine serum (FBS). On the 3rd day of culture, the cells were ready for the flow cytometric detection of Th17 cell differentiation.

Different concentrations of GTW together with all the inducible factors required for Th17 cell differentiation were added to the culture medium. Detection was conducted after a 3-day co-incubation. The experimental groups were as follows: i) neutral condition group: $\mathrm{CD} 4{ }^{+} \mathrm{CD} 62 \mathrm{~L}^{+} \mathrm{T}$ cells were seeded onto the culture plates coated only with anti-CD3 $(5 \mu \mathrm{g} / \mathrm{ml})$ and anti-CD28 $(2 \mu \mathrm{g} / \mathrm{ml})$ that provided a normal growth environment for the CD4 ${ }^{+} \mathrm{CD}_{62} \mathrm{~L}^{+} \mathrm{T}$ cells. The cells were cultured for 3 days; ii) Th17 polarizing condition group: $\mathrm{CD} 4{ }^{+} \mathrm{CD} 62 \mathrm{~L}^{+}$ $\mathrm{T}$ cells were seeded onto the culture plates coated with antiCD3 $(5 \mu \mathrm{g} / \mathrm{ml})$ and anti-CD28 $(2 \mu \mathrm{g} / \mathrm{ml})$, and inducible factors (TGF- $\beta 1$, IL-6, IL-1 $\beta$, anti-IL-2, anti-IL-4, anti-IFN- $\gamma$ and IL-23) were also added during the 3-day culture; and iii) GTW (16 $\mu \mathrm{g} / \mathrm{ml}$ ) group: the conditions of the Th17 polarizing group were used. $\mathrm{CD} 4{ }^{+} \mathrm{CD} 62 \mathrm{~L}^{+} \mathrm{T}$ cells were seeded onto the culture plates coated with anti-CD3 $(5 \mu \mathrm{g} / \mathrm{ml})$ and anti-CD28 $(2 \mu \mathrm{g} / \mathrm{ml})$, and all the inducible factors and $16 \mu \mathrm{g} / \mathrm{ml}$ GTW were also added during the 3 -day culture; iv) GTW $(1.6 \mu \mathrm{g} / \mathrm{ml})$ group: the conditions of the Th17 polarizing group were used. The specific steps were the same as the GTW $(16 \mu \mathrm{g} / \mathrm{ml})$ group; however, the dose of GTW was $1.6 \mu \mathrm{g} / \mathrm{ml}$; v) GTW $(0.16 \mu \mathrm{g} / \mathrm{ml})$ group: the specific steps were the same as the GTW $(1.6 \mu \mathrm{g} / \mathrm{ml})$ group; however, the dose of GTW was $0.16 \mu \mathrm{g} / \mathrm{ml}$.

Impact of GTW upon Th17 cell differentiation detected by flow cytometry. After 3 days of culture, the cells were stimulated and induced to secrete intracellular cytokines by PMA $(10 \mathrm{ng} / \mathrm{ml})$, ionomycin $(1 \mu \mathrm{g} / \mathrm{ml})$ and brefeldin A (BFA; $10 \mu \mathrm{g} / \mathrm{ml})$. After being cultured for $6 \mathrm{~h}$, the cells were first incubated with antimouse CD4-FITC antibody, and then permeabilized and stained with APC-labeled anti-mouse IL-17 antibody. The percentage of $\mathrm{CD} 4^{+} \mathrm{IL}-17^{+} \mathrm{T}$ cells was then analyzed on a flow cytometer in order to establish the differentiation rate of the Th17 cells.

Impact of GTW upon IL-17 secretion detected byenzyme-linked immunosorbent assay (ELISA). The levels of IL-17 secreted from Th17 cells were measured using a commercial IL-17 ELISA kit according to the manufacturer's instructions.

Reverse transcription-quantitative polymerase chain reaction $(R T-q P C R)$. Total RNA extraction from mouse skin was performed using TRIzol reagent according to the manufacturer's instructions (Invitrogen, Carlsbad, CA, USA). Following the generation of cDNA using a Reverse Transcription kit (CWbio Co., Ltd., Beijing, China), RT-qPCR was performed on a Roche 480 II detection system with SYBR-Green Supermix (Bio-Rad Laboratories, Hercules, CA, USA). The gene-specific primers are summarized in Table I. The gene expression levels were normalized to the housekeeping gene, $\beta$-actin, and data 
are represented as fold-changes according to the $2^{-\Delta \Delta \mathrm{Ct}}$ method, where $\Delta \mathrm{Ct}=\mathrm{Ct}_{\text {target gene }}-\mathrm{Ct}_{\beta \text {-actin }}$ and $\Delta \Delta \mathrm{Ct}=\Delta \mathrm{Ct}_{\text {induced }}-\Delta \mathrm{Ct}_{\text {reference }}$. $\Delta \mathrm{Ct}_{\text {reference }}$ was chosen as the normal mice skin sample. PCR was performed as follows: $95^{\circ} \mathrm{C}$ for $10 \mathrm{~min}$; 50 cycles of $95^{\circ} \mathrm{C}$ for $15 \mathrm{sec}$, and $60^{\circ} \mathrm{C}$ for $60 \mathrm{sec}$. Relative quantitative analysis was carried out using the $2^{-\Delta \Delta \mathrm{Ct}}$ method.

Westernblotanalysis. Wholecell lysates were prepared fromeach skin tissue sample and protein concentrations were estimated using a BCA protein assay kit (23235; Thermo Fisher Scientific, Rockford, IL, USA). Protein samples were separated by sodium dodecyl sulfate-polyacrylamide gel electrophoresis (SDS-PAGE; $10 \%$ gel) and transferred to a polyvinylidene difluoride (PVDF) membrane by electroblotting at $4^{\circ} \mathrm{C}$. The membranes were then blocked for $2 \mathrm{~h}$ at room temperature with $5 \%$ non-fat dried milk powder in TBS, $0.1 \%$ Tween-20 (TBST) before being probed with anti-phosphorylated (p-)STAT3 (Cat. no. 9134) in 1/2,000 dilution, or anti-STAT3 (Cat. no. 9132) at a 1/2,000 dilution (both from Cell Signaling Technology, Inc., Beverly, MA, USA) overnight at $4^{\circ} \mathrm{C}$. Subsequently, the membrane was exposed to horseradish peroxidase-conjugated secondary antibodies (Cell Signaling Technology, Inc.). The results were visualized using a chemiluminescence detection system (Pierce ECL Western Blotting Substrate Detection system; Thermo Fisher Scientific) and exposed to autoradiography film. GAPDH was used as the control. Target protein expression levels were analyzed using Quantity One v4.4.0 software (Bio-Rad Laboratories).

Statistical analysis. All quantitative data are shown as the means \pm SD. Comparisons between two groups were assessed using the Student's t-test, and comparisons among three or more group were evaluated using one-way analysis of variance (ANOVA) followed by post-hoc testing with SPSS 15.0 software. A P-value $<0.05$ was considered to indicate a statistically significant difference.

\section{Results}

GTW protects mice against the development of psoriasis-like lesions induced by $I M Q$. The anti-inflammatory effects of GTW were examined in a mouse model of IMQ-induced psoriasis-like lesions. Consistent with previous findings (16), psoriasis-like lesions exhibiting signs of erythema, increased thickness and scaling, were observed two or three days after initiating the topical application of IMQ to shaved skin on the dorsal area of the mice. The severity of these lesions increased with the duration of IMQ application (Fig. 1B). Similar lesions were not observed in the normal (vehicle-treated) mice (Fig. 1A, first panel on left).

By contrast, the severity of the skin lesions observed in the IMQ-exposed mice was reduced by the co-administration of GTW. In these mice, reduced redness, desquamation and thickness was observed from day 2 compared with the mice in the model group. The modified PASI scores showed that GTW treatment resulted in a concentration- and time-dependent inhibition of erythema, scaling, thickness and cumulative scores, with an almost $40 \%$ reduction in all the measured parameters at a dose of $40 \mathrm{mg} / \mathrm{kg}$ GTW (Fig. 1B).

Microscopic evaluation of H\&E-stained mouse skin sections obtained from the model group treated for 8 days with IMQ showed characteristic changes associated with psoriasis lesions, such as acanthosis (thickening of the epidermis), parakeratosis (presence of nuclei in the stratum corneum), desquamation and inflammatory infiltration. These characteristics were not observed in the skin sections obtained from the mice in the normal group (Fig. 1C). However, GTW treatment partially inhibited these characteristic changes associated with lesion development in the IMQ-exposed mice (Fig. 1C). Statistical analysis of epidermal thickness using ImagePro Plus software showed significant decreases in the epidermal thickness following GTW administration in the IMQ-exposed mice (Fig. 1D).

Hyperproliferation of keratinocytes was also monitored by IHC staining of PCNA. In the IMQ-exposed mice, PCNA was detected within keratinocytes throughout the different layers of the epidermis, which was indicative of active proliferation. However, similar to the normal group of mice (Fig. 2A, upper panels), PCNA-positive cells were mainly restricted to the basal layer of the epidermis in the IMQ plus GTW-treated mice although staining of the horny cell layer was seen in all samples (Fig. 2A, upper panels).

IHC staining of involucrin, a biological marker of terminally differentiated keratinocytes in the epidermis, showed typical expression in the stratum spinosum of the epidermis in normal mice (Fig. 2A, lower panels). By contrast, topical IMQ administration resulted in widespread involucrin expression throughout the epidermis. However, the expression of involucrin in the IMQ plus GTW-treated mice showed a similar pattern to that observed in the normal (vehicle-treated) mice. Apart from morphological and cellular observations, we also evaluated the mRNA expression of keratin 14 (K14) as a marker of hyperproliferative keratinocytes, using RT-qPCR. A significant increase in K14 mRNA expression was observed in the IMQ-exposed mice compared with that in the normal control mice. By contrast, a significant reduction $(>60 \%)$ in K14 mRNA expression was observed in the IMQ plus GTW-treated mice (Fig. 2B).

These results indicated that GTW significantly inhibited IMQ-induced abnormalities in keratinocytes.

GTW attenuates IMQ-induced inflammatory infiltration of T cells, neutrophils and macrophages. Psoriasis-like skin inflammation is the result of abnormal immune cell activity. The induction and distribution of $\mathrm{T}$ cells, neutrophils and macrophages infiltration is a hallmark of the development of psoriasis-like skin inflammation (16). As expected, a marked infiltration of both mononuclear and multinuclear cells was observed in the H\&E-stained skin sections from the IMQ-exposed mice (Fig. 3). To localize and quantify leukocyte populations in the skin, we performed IHC staining for CD3 (T cells), F4/80 (macrophages), and Gr-1 (neutrophils) (Fig. 3). The numbers of cells of each type for each high power field in normal skin (data not shown) were $1.23 \pm 0.32$ for $\mathrm{F} 4 / 80,3.37 \pm 0.68$ for $\mathrm{CD}^{+}$and $2.84 \pm 0.55$ for $\mathrm{Gr}-1$. There were significantly fewer $\mathrm{F} 4 / 80^{+}, \mathrm{CD}^{+}$and $\mathrm{Gr}-1^{+}$cells in samples from the IMQ plus GTW group $(11.85 \pm 3.79,15.88 \pm 0.99$ and $4.26 \pm 1.32$, respectively) compared with the number observed in the mice treated with IMQ alone $(52.00 \pm 5.86,43.49 \pm 2.14$ and 23.28 4 4. 56, respectively, all $\mathrm{P}<0.01$ ).

These data indicate that GTW suppressed the differentiation of immune cells induced by IMQ. 
A

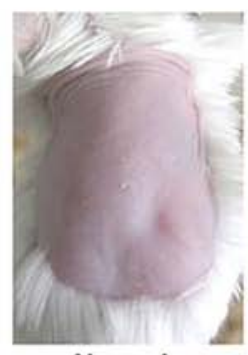

Normal

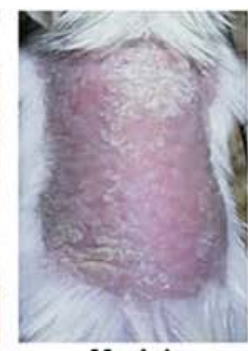

Model

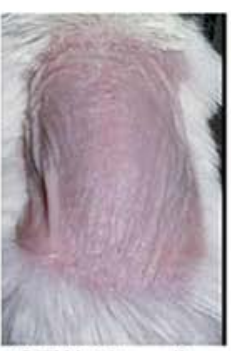

GTW 40 mg/kg

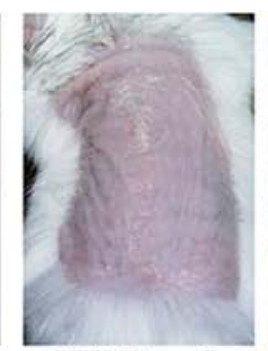

GTW 20 mg/kg

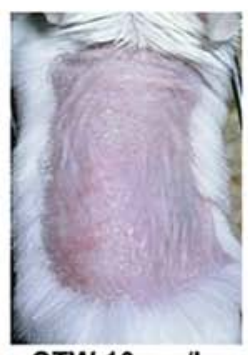

GTW $10 \mathrm{mg} / \mathrm{kg}$
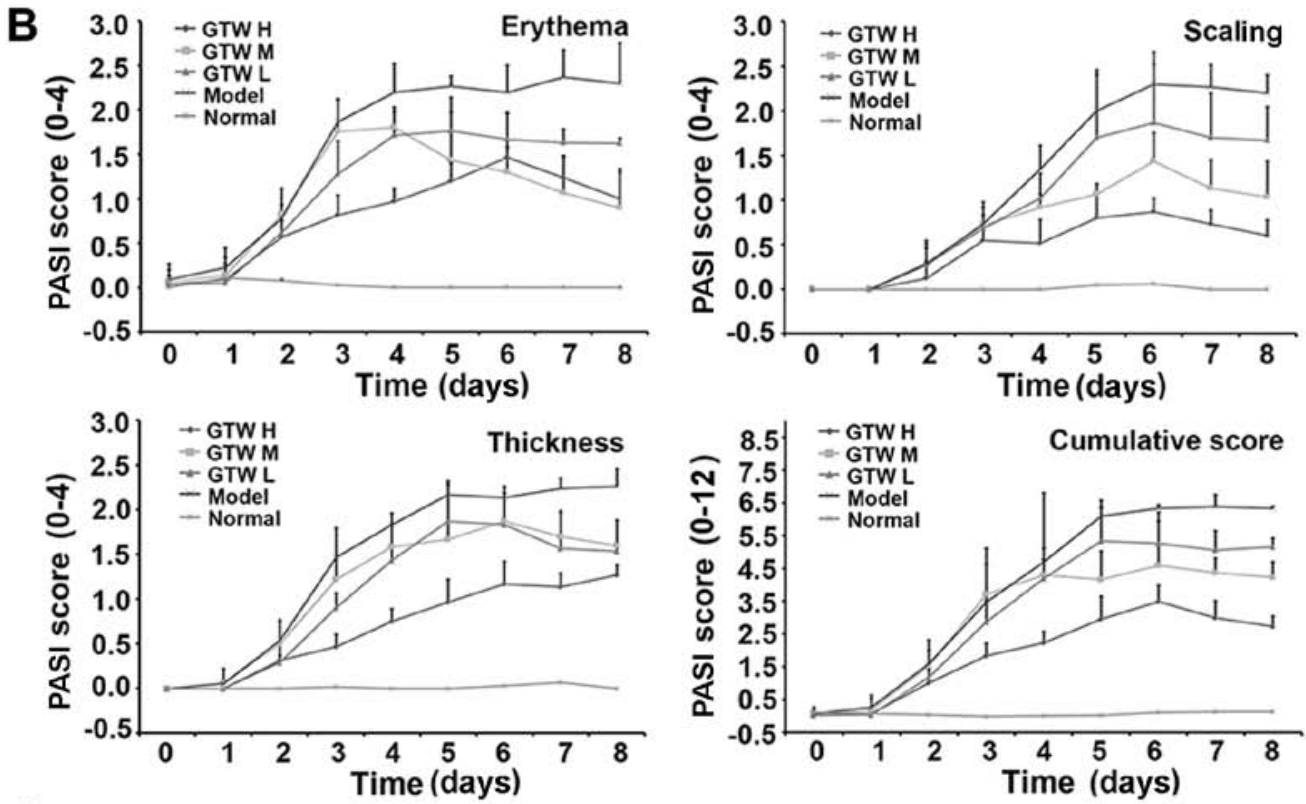

C

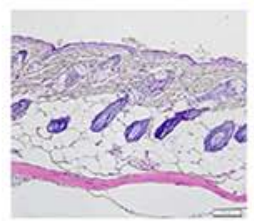

Normal

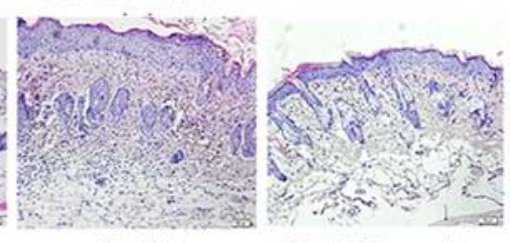

Model
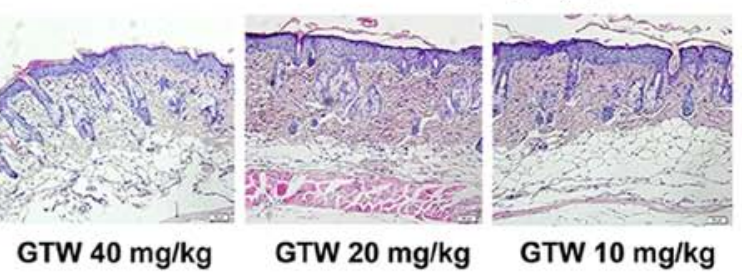

GTW $20 \mathrm{mg} / \mathrm{kg}$

GTW $10 \mathrm{mg} / \mathrm{kg}$

D

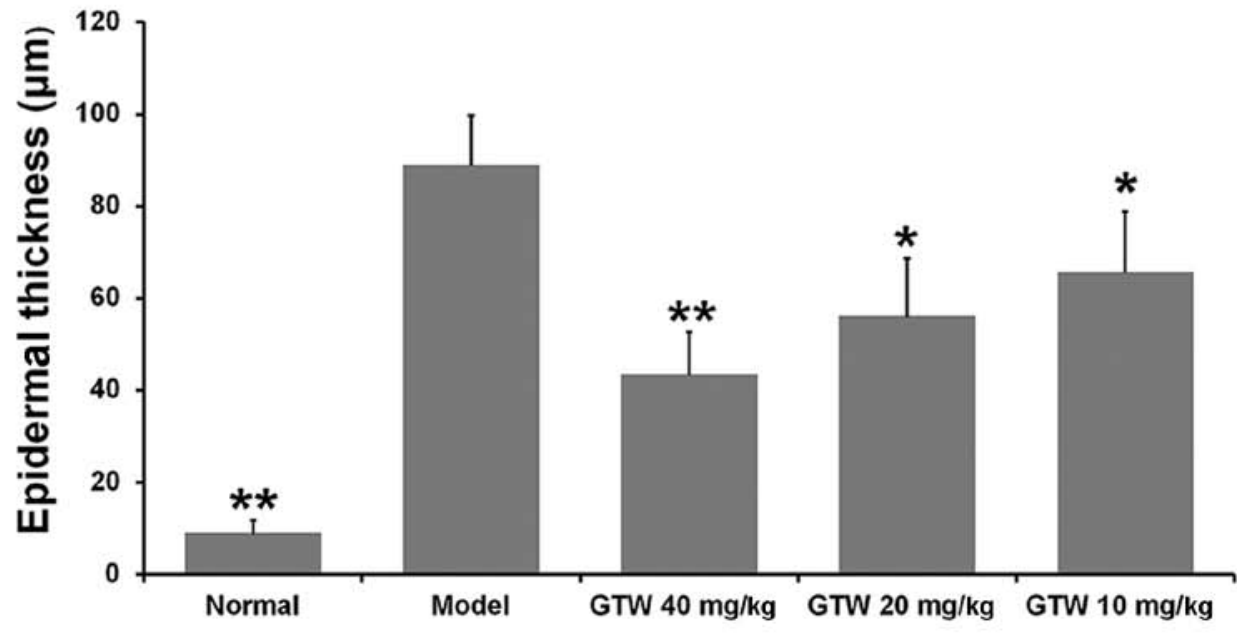

Figure 1. Therapeutic effect of multi-glycoside of T. wilfordii Hook. f. (GTW) on psoriasis-like lesions induced by imiquimod (IMQ) in mice. Vaseline was applied daily to BALB/c mice in the normal group and IMQ was applied daily to mice in the model and GTW-treated groups. The GTW groups were treated simultaneously with GTW (10, 20 and $40 \mathrm{mg} / \mathrm{kg}$ ) and IMQ. After 8 days, the mice were sacrificed for skin lesion analysis. (A) Phenotypical presentation of back skin of mice after 8 days of imiquimod treatment with the indicated compounds. Comparison of skin changes in each group. (B) Erythema, scaling, and thickness of the skin lesions were scored daily on a scale from 0 to 4 ( 0 , none; 1 , slight; 2, moderate; 3 , marked; 4, very marked). In addition, the cumulative score (erythema plus scaling plus thickness, scale 0-12) is depicted. Symbols indicate the means \pm SD (n=6/group). (C) Representative microscopic images of H\&E-stained skin sections from each group following 8 days of treatment. Acanthosis, parakeratosis, pustules and desquamation were observed in the model mice. Scale bar $=50 \mu \mathrm{m}$. (D) Epidermal thickness was evaluated using ImagePro Plus software under a microscope. Bars represent the means $\pm \mathrm{SD}$ ( $\mathrm{n}=6 / \mathrm{group}$ ). GTW H, 40 mg/kg; GTW M, 20mg/kg; GTW L, 10mg/kg. "P $<0.05$ and ${ }^{* *} \mathrm{P}<0.01$ vs. the model group. 
A
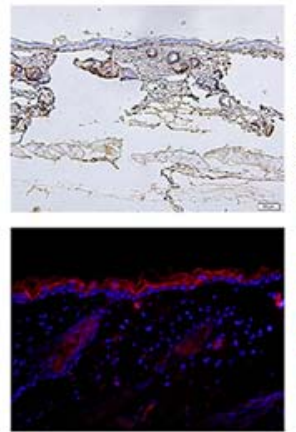

Normal
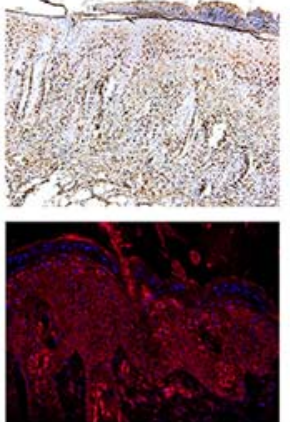

Model

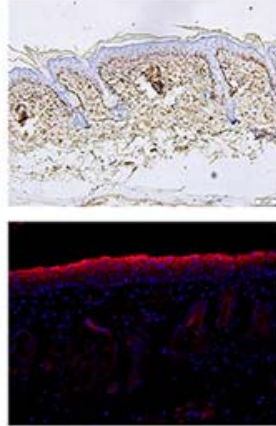

GTW

B

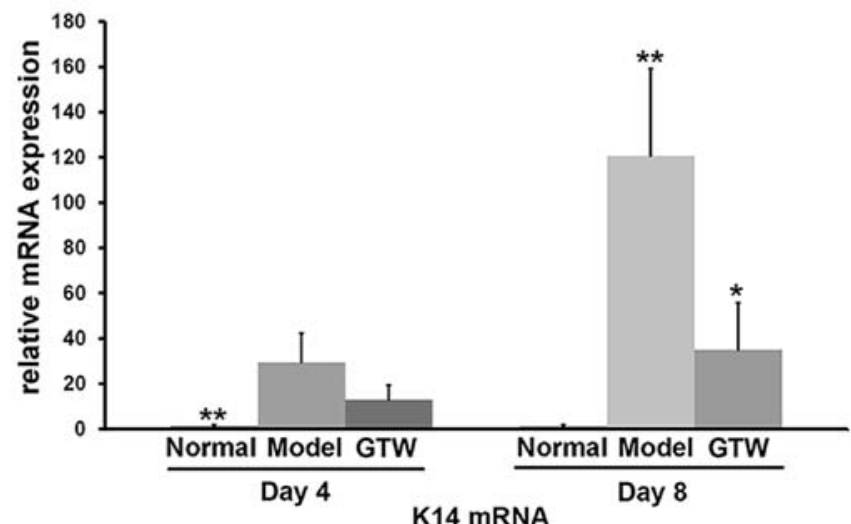

Figure 2. Immunohistochemical characteristics of keratinocytes and RT-qPCR analysis of keratin 14 (K14) mRNA expression. (A) Immunohistochemical characteristics of keratinocytes using the proliferation marker, proliferating cell nuclear antigen (PCNA) and DAB that stained the cells brown whereas hematoxylin stained the cells blue (upper panels) and the involucrin marker, with FITC that stained the positive cells red whereas the nuclei are stained blue with DAPI (lower panels) in the mouse skin tissue. Scale bar $=100 \mu \mathrm{m}$. Images are from the normal, model and multi-glycoside of T. wilfordii Hook. f. (GTW) (40 mg/kg) groups on day 8. (B) RT-qPCR of K14 mRNA. RNA was isolated from two different pieces of back skin. Data represent the means \pm SD of two replicated experiments with four samples ( $\mathrm{n}=8)$ per group from normal, model and GTW $(40 \mathrm{mg} / \mathrm{kg})$ groups at days 4 and 8 . ${ }^{*} \mathrm{P}<0.05$ and ${ }^{* *} \mathrm{P}<0.01$ vs. the model group.
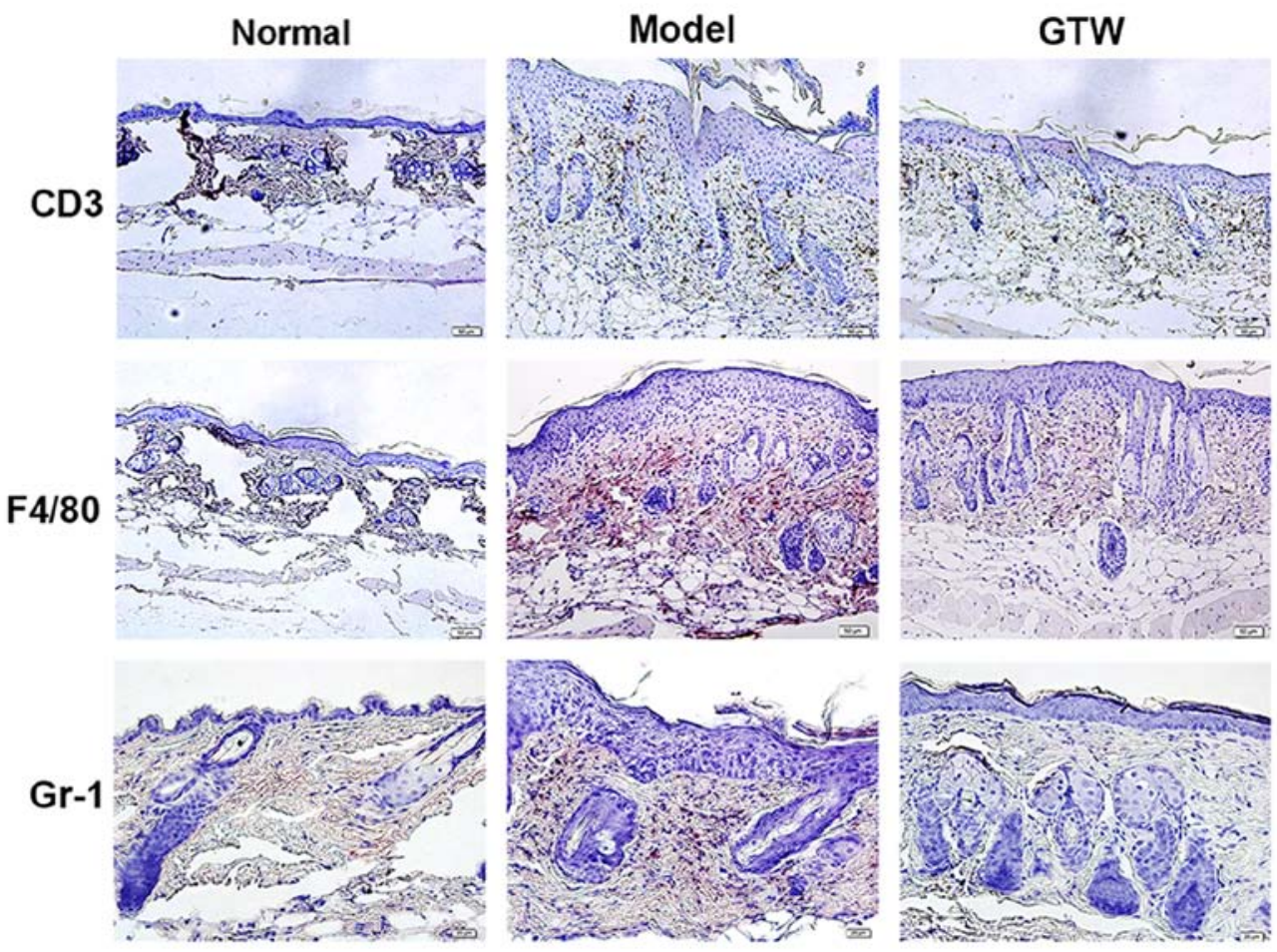

Figure 3. Induction and distribution of T cells, neutrophils and macrophages infiltration in imiquimod and/or multi-glycoside of T. wilfordii Hook.f. (GTW)-treated $(40 \mathrm{mg} / \mathrm{kg})$ mice. Skin tissue was stained using the immunohistochemical method on day 8 . The composition of the leukocyte infiltration was visualized using antibodies to the following markers: CD3 (T cells), F4/80 (macrophages) and Gr-1 (neutrophils). Representative sections of six samples from the normal, model or GTW $(40 \mathrm{mg} / \mathrm{kg})$ groups are shown. 

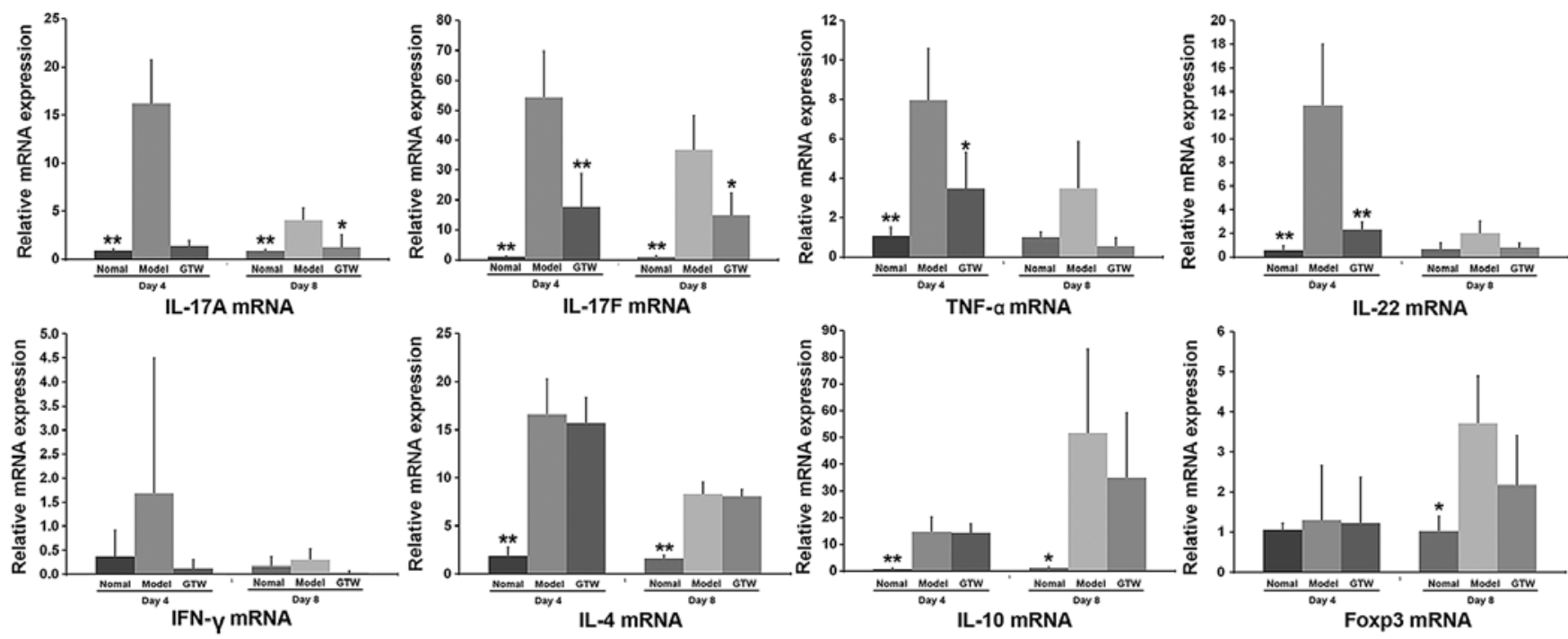

Figure 4. RT-qPCR of proinflammatory cytokines in Th17 cells isolated from imiquimod (IMQ) and/or multi-glycoside of T. wilfordii Hook. f. (GTW)-treated mouse skin. RNA was isolated from two different pieces of skin. Data represent the means \pm SD of two replicated experiments with four samples ( $=8$ ) per group from the normal, model and GTW (40 mg/kg) groups at days 4 and 8 . ${ }^{*} \mathrm{P}<0.05$ and ${ }^{* *} \mathrm{P}<0.01$ versus the model group.

GTW suppresses the expression of Th17-type proinflammatory cytokines in IMQ-exposed skin. To characterize the immunosuppressive effect of GTW on IMQ-induced skin lesions, the mRNA expression levels of a number of cytokines were determined by RT-qPCR (Fig. 4).

Compared with the normal control mice, the mRNA expression levels of Th17-type cytokines, including IL-17A, IL-17F, IL-22 and TNF- $\alpha$, were markedly increased in the skin of the IMQ-exposed mice after 4 days (Fig. 4), although the mRNA levels of all these cytokines decreased after 8 days. However, a clear suppressive effect on the mRNA expression levels of these cytokines in the psoriasis-like lesions was observed in the IMQ plus GTW-treated mice. GTW almost abolished the transcription levels of IL-17A, TNF- $\alpha$ and IL-22, which were similar to the levels observed in the vehicletreated control mice. However, the mRNA level of IL-17F was reduced by only 50\% (approximately) in the IMQ plus GTW group compared with the IMQ-exposed group.

By contrast, the mRNA expression of the Th1 type cytokine, IFN- $\gamma$, was not significantly induced by IMQ at any of the time points (days 1,2, 4, 6 and 8), with expression levels remaining similar to those observed in control mice (data not shown). GTW had no effect on the mRNA expression of IFN- $\gamma$.

The mRNA expression of IL-4, IL-10 and Foxp3 (a Treg cell transcription factor) was significantly induced by IMQ, although GTW did not inhibit their expression after treatment for 4 or 8 days (Fig. 4).

Unexpectedly, an increase in the mRNA expression of IL-10 and Foxp3 mRNA expression was observed at day 8 in the IMQ-exposed mice compared with that in the normal mice. However, there was no significant difference between the IMQ-exposed and the IMQ plus GTW-treated mice.

GTW decreases Th17 cell numbers in the spleens of $I M Q$-exposed mice. Significant spleen enlargement, with a near three-fold increase in splenic mass, was observed in the IMQ-exposed mice after 8 days (Fig. 5A). A significantly lower splenic mass was recorded in the mice treated with IMQ plus GTW, which was similar to that observed in the normal group.

To determine the percentages of Th1, Th2, Th17 and Treg cells in the spleen, the splenic cells were activated ex vivo by PMA and ionomycin for $5 \mathrm{~h}$, stained intracellularly for IFN- $\gamma$, IL-4, IL-17A and Foxp3, and analyzed using flow cytometry. Topical IMQ administration induced an increased percentage of splenic $\mathrm{CD}^{+}$and IL-17A ${ }^{+} \mathrm{T}$ cells compared with that in the normal mice at day 8 (Fig. 5B). By contrast, the percentage of $\mathrm{CD} 4^{+}$and IFN- $\gamma^{+} \mathrm{T}$ cells, as well as $\mathrm{CD}^{+}$and $\mathrm{IL}-4^{+} \mathrm{T}$ cells, was only marginally decreased. Notably, increased percentages of splenic $\mathrm{CD} 4^{+} \mathrm{CD} 25^{+}$Foxp $^{+}$Treg cells were found in the IMQ-exposed mice compared with that in the normal group (Fig. 5B). GTW administration resulted in the marked suppression of the percentage of IMQ-induced CD4 ${ }^{+}$IL-17A ${ }^{+}$ T cells. However, GTW was not found to affect the proportion of $\mathrm{CD}^{+} \mathrm{IFN}^{-} \gamma^{+} \mathrm{T}$ cells, $\mathrm{CD} 4^{+} \mathrm{IL}_{-} 4^{+} \mathrm{T}$ cells and $\mathrm{CD} 4^{+} \mathrm{CD} 25^{+}$ Foxp $3^{+}$Treg cells.

As the source of IL-17 may not be Th17 cells but $\gamma \delta \mathrm{T}$ cells, we also evaluated the numbers of $\gamma \delta T$ cells. Unfortunately, there were too few to detect in the spleen samples so we detected their levels in $\mathrm{T}$ cells isolated from lymph nodes. The results showed $3.03 \pm 1.00 \%$ in the normal mice and $7.58 \pm 2.49 \%$ in the IMQ-exposed mice, which was a significant increase $(\mathrm{P}<0.01)$. However, the numbers following GTW treatment were not significantly decreased $(7.09 \pm 3.21 \%$ ) (data not shown).

These data indicated that the effect of GTW was mediated through Th17 cells rather than Th1, Th2 or Treg cells.

$G T W$ decreases $\gamma \delta T$ cells in the dermis of IMQ-exposed mice. We assessed the number of $\gamma \delta \mathrm{T}$ cells in mouse skin by performing IHC staining. The results showed that the number of $\gamma \delta T$ cells in the dermis of mice with IMQ-induced psoriasis was significantly decreased following GTW treatment (Fig. 6).

In vitro observation and identification of Th17 cells. After a 3-day culture with naive $\left(\mathrm{CD} 4{ }^{+} \mathrm{CD} 62 \mathrm{~L}^{+}\right) \mathrm{T}$ cells sorted by the 

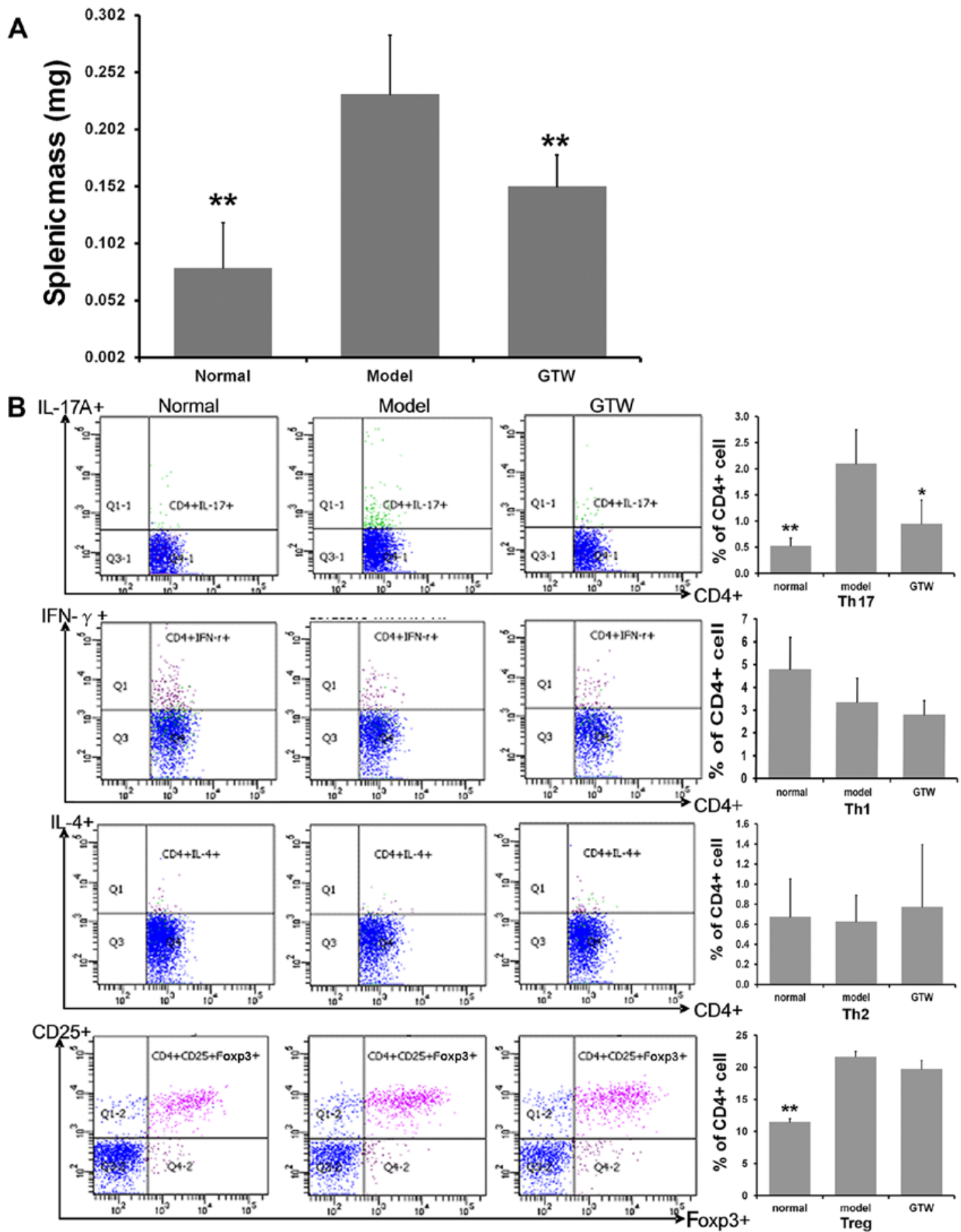

Figure 5. (A) Determination of splenic mass. The mice from the normal, model or multi-glycoside of $T$ wilfordii Hook. f. (GTW) ( $40 \mathrm{mg} / \mathrm{kg}$ ) groups were sacrificed at day 8 in order to determine splenic mass. (B) Flow cytometric analysis of splenic cells following imiquimod (IMQ) and/or GTW treatment. Splenic cells from the normal, model or GTW $(40 \mathrm{mg} / \mathrm{kg}$ ) groups at day 8 were isolated. Splenic cells were stimulated in vitro for $5 \mathrm{~h}$ with phorbol myristate acetate (PMA) and ionomycin, and analyzed using flow cytometry for intracellular interleukin (IL)-17A, interferon- $\gamma$ (IFN- $\gamma$ ), IL-4 and Foxp3 expression. A representative example is shown. Numbers indicate the mean percentage of cells $\pm \mathrm{SD}$ present within a quadrant ( $\mathrm{n}=4$ mice/group). ${ }^{*} \mathrm{P}<0.05$ and ${ }^{* * *} \mathrm{P}<0.01$ versus the model group.

magnetic beams under a neutral condition and Th17 polarizing condition, the cells were observed using an inverted microscope. Under the neutral condition, the cells were growing in a good state, with visible cell clusters that met with the growth characteristics of $\mathrm{T}$ cells. Under the Th17 polarizing condition, the $\mathrm{T}$ cells were slightly enlarged with abundant and large cell clusters and increased cell numbers. The results of flow cytometric analysis indicated a $1.45 \pm 0.73$ and $21.45 \pm 1.92 \%$ (data not shown) fraction of the Th17 $\left(\mathrm{CD} 4^{+} \mathrm{IL}-17^{+}\right)$in the naive
T cells under the neutral condition and Th17 polarizing condition, respectively; thus, a significant difference was observed between the two groups $(\mathrm{P}<0.01)$.

The results of the ELISA indicated a significantly higher IL-17 secretion level in the Th17 polarizing condition group than in the neutral condition group $(\mathrm{P}<0.05)$ and significantly lower IL-17 secretion levels in all the GTW groups than in the Th17 polarizing condition group (data not shown; all $\mathrm{P}<0.05)$. 


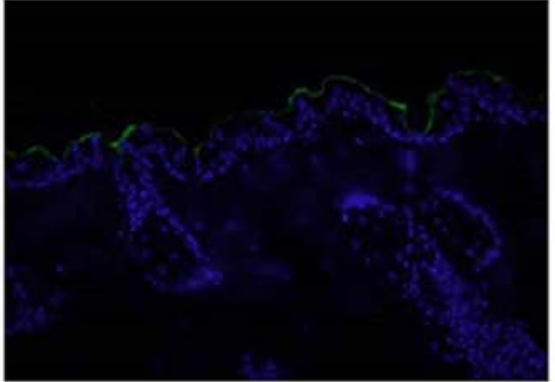

Normal

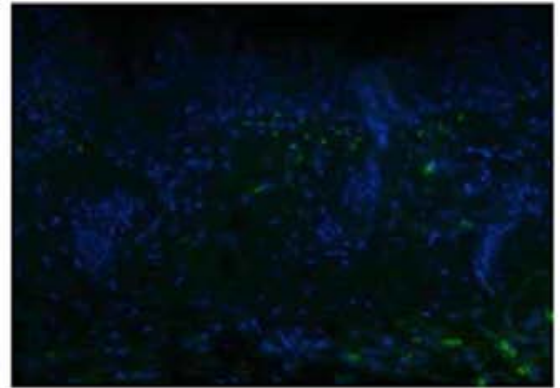

Model

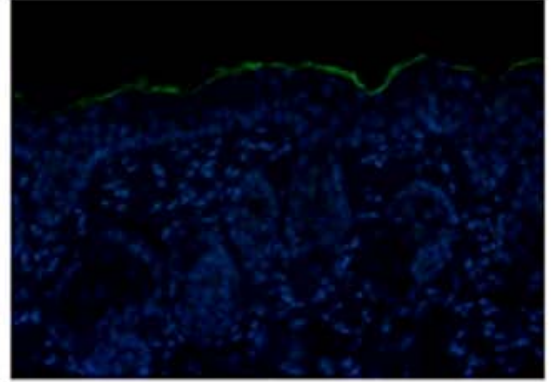

GTW

Figure 6. Immunohistochemical analysis of $\gamma \delta \mathrm{T}$ cells in the dermis of mice from the normal, model or multi-glycoside of $T$. wilfordii Hook. f. (GTW) groups. The positive cells are stained green and DAPI labeling is blue to identify nuclei. Magnification, $\mathrm{x} 400$.

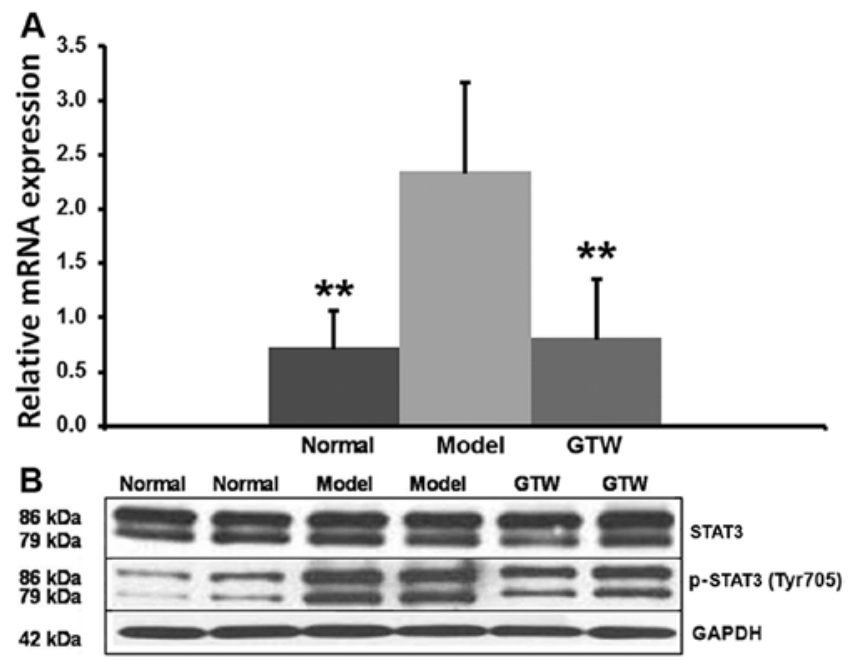

Figure 7. RT-qPCR of retinoic acid-related orphan receptor $\gamma \mathrm{t}(\mathrm{ROR} \gamma \mathrm{t})$ transcription and western blot analysis of STAT3 phosphorylation. (A) mRNA Expression of ROR $\gamma \mathrm{t}$ was normalized with $\beta$-actin expression by densitometry. (B) STAT3 and phosphorylated (p)-STAT3 expression in the normal, model or multi-glycoside of $T$. wilfordii Hook. f. (GTW) $(40 \mathrm{mg} / \mathrm{kg})$ groups was evaluated by western blot analysis. Data are presented as the means $\pm S D, n=4$ ${ }^{* *} \mathrm{P}<0.01$ versus the model group. The results were pooled from two replicated experiments with four samples per group.

GTW inhibits the expression of retinoic acid-related orphan receptor $(R O R) \gamma t$ and STAT3 phosphorylation in IMQ-exposed mice. The transcription factor ROR $\gamma \mathrm{t}$ critically regulates IL-17 production in Th17 cells. High mRNA levels of ROR $\gamma \mathrm{t}$ were observed in the IMQ-induced mice skin lesions and were decreased by the co-administration of GTW (Fig. 7A). STAT3 is a critical factor which is involved in Th17 differentiation through the regulation of IL-17 and ROR $\gamma \mathrm{t}$. The semi-quantitative analysis (data not shown) of the blots suggested that the relative expression levels of STAT3 were $0.983 \pm 0.107$ for normal mice, $0.871 \pm 0.257$ for IMQ-exposed mice and $0.784 \pm 0.304$ for GTW-treated mice, and the differences were not significant between the groups. However, STAT3 phosphorylation was significantly increased $(\mathrm{P}<0.01)$ in the IMQ-exposed mice, to a level of $1.348 \pm 0.371$ compared with $0.235 \pm 0.137$ in the normal mice. Analysis of the effects of GTW on STAT3 activation indicated that GTW treatment resulted in $0.673 \pm 0.126$ relative levels showing significantly reduced $(\mathrm{P}<0.01)$ STAT3 phosphorylation compared with that in the IMQ-exposed mice (Fig. 7B).

\section{Discussion}

The Th17 cell response is considered to play a major role in the pathogenesis of psoriasis. Th17 cells have been implicated in the formation of IMQ-induced psoriatic lesions in a mouse model (16). Thus, in this study, we aimed to examine the known anti-inflammatory effects of GTW in a mouse model, in order to further elucidate the mechanism which is responsible for the anti-inflammatory effects of GTW and protects against the formation of IMQ-induced psoriasis-like lesions. Our results showed that GTW protected mice from developing psoriasis-like lesions induced by topical IMQ administration. Furthermore, our data indicated that this protection was achieved by inhibiting Th17 cells rather than Th1, Th2 or Treg cells, and GTW suppressed Th17 function through the inhibition of STAT3 phosphorylation.

The Th17 response is considered to play a major role in psoriasis due to the increased activity of Th17 cells and Th17-related cytokines in cutaneous lesions and in the serum of patients with psoriasis (17-20).

In the present study, no apparent toxicity was observed in the mice administered GTW intragastrically for 8 days at doses of 10, 20 and $40 \mathrm{mg} / \mathrm{kg}$ (data not shown).

IMQ-induced psoriasis-like lesions in mice share a substantial number of major hallmarks with human psoriatic plaques in terms of histopathological and molecular features. In the present study, inflammation was observed in the IMQ-exposed mouse skin from days 2-3 onward, with significant thickening, erythema and scaling of the skin, reaching peak severity at days 7-8. These symptoms diminished gradually after 10-12 days (data not shown). GTW exhibited protective activity against the formation of IMQ-induced psoriasiform lesions at all time-points. Furthermore, histopathological analysis confirmed that GTW prevented the abnormal differentiation and proliferation of keratinocytes induced by IMQ compared with the control mice, and flow cytometric analysis revealed reduced inflammatory cell infiltration. However, a major difference in K14 expression was observed in the present study compared with that which has been observed in human psoriasis lesions; it is generally agreed that K14 expression is downregulated in psoriasis lesions, and this may be one of the mechanisms through which the lesions develop (21). The results in this study demonstrated that K14 expression was upregulated in IMQ-induced psoriasiform lesions and then 
downregulated by GTW treatment. This suggests that alternative mechanisms may be responsible for these effects which occurred in our mouse model compared with those which occur in human psoriatic plaques.

In the present study, comparisons with normal mice revealed significantly increased levels of Th17 cytokines, such as IL-17A, IL-17F and IL-22 mRNAs in the skin samples, and IL-17-secreting splenic CD4 ${ }^{+}$lymphocytes in the IMQ-exposed mice. Taken together, these findings confirmed that the Th17 cell immune response was activated in a mouse model of IMQ-induced psoriasis-like lesions. GTW exerted suppressive effects on the Th17 response in this model. Notably, the mRNA levels of IL-10 and Foxp3 were increased in the skin of the IMQ-exposed mice in combination with a greater number of $\mathrm{CD}^{+}{ }^{+} \mathrm{CD} 25^{+} \mathrm{Foxp}^{+} \mathrm{T}$ cells in the spleen, which is in accordance with the results of a previous study (22).

The balance between an efficient immune response and pathological damage is maintained by the interplay between Treg and effector $\mathrm{T}$ cells. We hypothesized that this balance is upset in psoriasis by increased Th17 cell infiltration, leading to concomitant Treg recruitment that acts as a feedback mechanism to inhibit the hyper-immune response in IL-17-induced inflammation at the lesion sites (22). This may account for the increase in the number of Treg cells in IMQ-induced psoriasis-like lesions in mice skin. By contrast, van der Fits et al demonstrated only a marginal increase in the percentage of splenic $\mathrm{CD} 4^{+} \mathrm{IFN} \gamma^{+} \mathrm{T}$ cells in IMQ-exposed mice compared with normal mice, although in contrast to our data, they reported increased percentages of splenic CD4 ${ }^{+} \mathrm{IL}-4^{+} \mathrm{T}$ cells (16). These discrepancies may be due to technical differences between these studies.

Emerging evidence has shown that high levels of IL-17 are produced by dermal $\gamma \delta$ T cells following IL-23 stimulation and that these cells play a major role in the pathology of psoriasis $(23,24)$. Thus, we also performed a preliminary investigation into $\gamma \delta$ T cells. The results showed that although the levels of $\gamma \delta \mathrm{T}$ cells were too low to detect with our flow cytometry method in the spleen, levels in the lymph nodes were clearly increased with IMQ induction; however, in this study, GTW had no significant effect on these cell numbers. IHC staining showed that the increased numbers of the $\gamma \delta \mathrm{T}$ cells in the dermis of mice with IMQ-induced psoriasis were then decreased with GTW treatment. Thus, these results suggest an important localized role for $\gamma \delta \mathrm{T}$ cells and that further investigation is warranted, to fully understand the interaction between $\gamma \delta$ T cells and GTW treatment in psoriasis.

In our experiments, GTW did not exert a statistically significant effect on the proportion of $\mathrm{CD}^{+} \mathrm{IFN}-\gamma^{+} \mathrm{T}$ cells, $\mathrm{CD} 4{ }^{+} \mathrm{IL}-4^{+} \mathrm{T}$ cells and $\mathrm{CD} 4^{+} \mathrm{CD} 25^{+}$Foxp $3^{+}$Treg cells in the spleen cells. Taken together with the unchanged mRNA levels of Th1 cytokine IFN $\gamma$, Th2 cytokine IL-4 and Treg cytokine IL-10 in IMQ-exposed mouse skin after GTW administration, these findings suggest that the immunosuppressive effect of GTW in psoriasis is exerted mainly on Th17 cells, rather than on Th1, Th2 or Treg cells.

It has been proposed that ROR $\gamma \mathrm{t}$ is a 'master regulator' of Th17 cell differentiation (25). ROR $\gamma$ t deficiency has been reported to result in a profound loss of function in Th17 cells and to attenuate autoimmune development in an animal model of experimental autoimmune encephalomyelitis (26). STAT3 is required for multiple functions in Th17 cells such as gene expression of IL-17 and ROR $\gamma \mathrm{t}(27,28)$. It has been reported that homodimerization and nuclear translocation of p-STAT3 protein induced the transcription of ROR $\gamma \mathrm{t}$ and Th17 cytokines, such as IL-17A, IL-17F and IL-22 (6). We demonstrated that GTW inhibited STAT3 phosphorylation and markedly reduced the mRNA levels of ROR $\gamma \mathrm{t}$, IL-17A, IL-17F and IL-22 in a mouse model of IMQ-induced psoriasis-like lesions. As Th17 cytokines recruit neutrophils, the level of Gr-1+ $1^{+}$cells in IMQ-exposed mouse skin may be affected by the repressed expression of IL-17, which is consistent with the results shown in Fig. 3.

In conclusion, our data indicate that GTW inhibits the formation of IMQ-induced skin lesions by downregulating the function of Th17 cells rather than Th1, Th2 or Treg cells, and that GTW suppresses Th17 function through the inhibition of STAT3 phosphorylation.

\section{Acknowledgements}

The present study was supported by the National Natural Science Foundation of China (nos. 81072810 and 81302985), and the Beijing Science and Technology Projects (no. D08050703550901).

\section{References}

1. Chan JR, Blumenschein W, Murphy E, Diveu C, Wiekowski M, Abbondanzo S, Lucian L, Geissler R, Brodie S, Kimball AB, et al: IL-23 stimulates epidermal hyperplasia via TNF and IL-20R2-dependent mechanisms with implications for psoriasis pathogenesis. J Exp Med 203: 2577-2587, 2006.

2. Rácz E, Kurek D, Kant M, Baerveldt EM, Florencia E, Mourits S, de Ridder D, Laman JD, van der Fits L and Prens EP: GATA3 expression is decreased in psoriasis and during epidermal regeneration; induction by narrow-band UVB and IL-4. PLoS One 6: e19806, 2011.

3. Lowes MA, Bowcock AM and Krueger JG: Pathogenesis and therapy of psoriasis. Nature 445: 866-873, 2007.

4. Gaspari AA: Innate and adaptive immunity and the pathophysiology of psoriasis. J Am Acad Dermatol 54 (Suppl 2): S67-S80, 2006.

5. Lew W, Bowcock AM and Krueger JG: Psoriasis vulgaris: cutaneous lymphoid tissue supports T-cell activation and 'Type 1' inflammatory gene expression. Trends Immunol 25: 295-305, 2004

6. Di Cesare A, Di Meglio P and Nestle FO: The IL-23/Th17 axis in the immunopathogenesis of psoriasis. J Invest Dermatol 129: 1339-1350, 2009.

7. Blauvelt A: T-helper 17 cells in psoriatic plaques and additional genetic links between IL-23 and psoriasis. J Invest Dermatol 128: 1064-1067, 2008.

8. Pène J, Chevalier S, Preisser L, Vénéreau E, Guilleux MH, Ghannam S, Molès JP, Danger Y, Ravon E, Lesaux S, et al: Chronically inflamed human tissues are infiltrated by highly differentiated Th17 lymphocytes. J Immunol 180: 7423-7430, 2008.

9. McGeachy MJ, Chen Y, Tato CM, Laurence A, Joyce-Shaikh B, Blumenschein WM, McClanahan TK, O'Shea JJ and Cua DJ: The interleukin 23 receptor is essential for the terminal differentiation of interleukin 17-producing effector $\mathrm{T}$ helper cells in vivo. Nat Immunol 10: 314-324, 2009.

10. Tonel G, Conrad C, Laggner U, Di Meglio P, Grys K, McClanahan TK, Blumenschein WM, Qin JZ, Xin H, Oldham E, et al: Cutting edge: a critical functional role for IL-23 in psoriasis. J Immunol 185: 5688-5691, 2010.

11. Mabuchi T, Takekoshi T and Hwang ST: Epidermal CCR6 ${ }^{+}$ $\gamma \delta \mathrm{T}$ cells are major producers of IL-22 and IL-17 in a murine model of psoriasiform dermatitis. J Immunol 187: 5026-5031, 2011.

12. Johnson-Huang LM, Suárez-Fariñas M, Sullivan-Whalen M, Gilleaudeau P, Krueger JG and Lowes MA: Effective narrow-band UVB radiation therapy suppresses the IL-23/IL-17 axis in normalized psoriasis plaques. J Invest Dermatol 130: 2654-2663, 2010. 
13. Nograles KE, Davidovici B and Krueger JG: New insights in the immunologic basis of psoriasis. Semin Cutan Med Surg 29: 3-9, 2010.

14. Wan Y, Gu L, Suzuki K, Karasawa T, Fujioka Y, Han GD, Koike H, Kawachi H and Shimizu F: Multi-glycoside of Tripterygium wilfordii Hook.f. ameliorates proteinuria and acute mesangial injury induced by anti-Thyl.1 monoclonal antibody. Nephron, Exp Nephrol 99: e121-e129, 2005.

15. Zhan QX and Xu LM: Effiency of Tripterygium Wilfordii on treating psoriasis:A systematic review. Chin J Dermatovenerol Integr Trad West Med 6: 192-196, 2007.

16. van der Fits L, Mourits S, Voerman JS, Kant M, Boon L, Laman JD, Cornelissen F, Mus AM, Florencia E, Prens EP and Lubberts E: Imiquimod-induced psoriasis-like skin inflammation in mice is mediated via the IL-23/IL-17 axis. J Immunol 182 5836-5845, 2009.

17. Kagami S, Rizzo HL, Lee JJ, Koguchi Y and Blauvelt A: Circulating Th17, Th22, and Th1 cells are increased in psoriasis. J Invest Dermatol 130: 1373-1383, 2010.

18. Lowes MA, Kikuchi T, Fuentes-Duculan J, Cardinale I, Zaba LC, Haider AS, Bowman EP and Krueger JG: Psoriasis vulgaris lesions contain discrete populations of Th1 and Th17 T cells. J Invest Dermatol 128: 1207-1211, 2008.

19. Harper EG, Guo C, Rizzo H, Lillis JV, Kurtz SE, Skorcheva I, Purdy D, Fitch E, Iordanov M and Blauvelt A: Th17 cytokines stimulate CCL20 expression in keratinocytes in vitro and in vivo: implications for psoriasis pathogenesis. J Invest Dermatol 129: 2175-2183, 2009.

20. Yilmaz SB, Cicek N, Coskun M, Yegin O and Alpsoy E: Serum and tissue levels of IL-17 in different clinical subtypes of psoriasis. Arch Dermatol Res 304: 465-469, 2012.

21. Ota T, Takekoshi S, Takagi T, Kitatani K, Toriumi K, Kojima T, Kato M, Ikoma N, Mabuchi T and Ozawa A: Notch signaling may be involved in the abnormal differentiation of epidermal keratinocytes in psoriasis. Acta Histochem Cytochem 47: 175-183, 2014.
22. Zhang L, Yang XQ, Cheng J, Hui RS and Gao TW: Increased Th17 cells are accompanied by FoxP3(+) Treg cell accumulation and correlated with psoriasis disease severity. Clin Immunol 135: 108-117, 2010.

23. Cai Y, Shen X, Ding C, Qi C, Li K, Li X, Jala VR, Zhang HG, Wang T, Zheng $\mathrm{J}$ and Yan J: Pivotal role of dermal IL-17producing $\gamma \delta \mathrm{T}$ cells in skin inflammation. Immunity 35: 596-610, 2011.

24. Pantelyushin S, Haak S, Ingold B, Kulig P, Heppner FL, Navarini AA and Becher B: Ror $\gamma \mathrm{t}^{+}$innate lymphocytes and $\gamma \delta \mathrm{T}$ cells initiate psoriasiform plaque formation in mice. $\mathrm{J}$ Clin Invest 122: 2252-2256, 2012.

25. O'Shea JJ, Steward-Tharp SM, Laurence A, Watford WT, Wei L, Adamson AS and Fan S: Signal transduction and Th17 cell differentiation. Microbes Infect 11: 599-611, 2009.

26. Dong C: TH17 cells in development: an updated view of their molecular identity and genetic programming. Nat Rev Immunol 8: 337-348, 2008.

27. Li Y, Yu C, Zhu WM, Xie Y, Qi X, Li N and Li JS: Triptolide ameliorates IL-10-deficient mice colitis by mechanisms involving suppression of IL-6/STAT3 signaling pathway and down-regulation of IL-17. Mol Immunol 47: 2467-2474, 2010

28. Gomez-Rodriguez J, Sahu N, Handon R, Davidson TS, Anderson SM, Kirby MR, August A and Schwartzberg PL: Differential expression of interleukin-17A and $-17 \mathrm{~F}$ is coupled to $\mathrm{T}$ cell receptor signaling via inducible $\mathrm{T}$ cell kinase. Immunity 31 : 587-597, 2009. 